\title{
Freezing Tolerance Attributes during Spring Deacclimation for Three Asparagus Cultivars with Varying Adaptation to Southern Ontario
}

\author{
Mahmoud Panjtandoust and David J. Wolyn ${ }^{1}$ \\ Department of Plant Agriculture, University of Guelph, Guelph, ON, Canada N1G 2W1
}

\begin{abstract}
Additional INDEX words. Asparagus officinalis, dehardening, $\mathrm{LT}_{50}$, winterhardiness
Abstract. Winterhardiness in asparagus (Asparagus officinalis) may be related to proper cold acclimation and induction of freezing tolerance in the fall, levels and maintenance of freezing tolerance in the winter, and the timing of deacclimation in the spring. Premature deacclimation and the inability to reacclimate could result in crown damage from spring freeze-thaw cycles. A field experiment was conducted, replicated over 2 years, to determine how three cultivars with varying adaptation to southern Ontario deacclimate in the spring by assessing $\mathbf{L T}_{50}$ (the temperature at which $\mathbf{5 0 \%}$ of plants die) and biochemical and physiological parameters associated with freezing tolerance. 'UC 157' (UC), the least-adapted cultivar, deacclimated after soil temperatures rose above freezing; $\mathbf{L T}_{\mathbf{5 0}}$ values increased linearly over time and were unaffected by fluctuations in soil temperature. 'Jersey Giant' (JG), a cultivar with moderate adaptation, rapidly deacclimated with increased soil temperature but appeared to partially reacclimate as temperatures decreased. For 'Guelph Millennium' (GM), the most-adapted cultivar, $\mathbf{L T}_{50}$ values did not change, maintaining the greatest levels of freezing tolerance during the spring sampling period. Although $\mathbf{L T}_{50}$ values did not differ among cultivars on the first spring sampling date, ranking for freezing tolerance at the final sampling in each year was GM $>J G>U C$, which is consistent with adaptation. Rhizome traits were most associated with freezing tolerance and included high concentrations of low-molecularweight fructans (LFs), glucose, and proline and low percentage water and sucrose concentration. Overall, data suggest that the timing of deacclimation and loss of freezing tolerance in the spring may significantly affect winterhardiness; cultivars that lose freezing tolerance early and cannot reacclimate could suffer most from late spring freeze-thaw cycles.
\end{abstract}

In temperate climates, asparagus phenology includes the induction of fern senescence and crown dormancy in the fall, quiescence in the winter, and regrowth in the spring. For optimal survival, plants must acquire adequate freezing tolerance, which is maintained during the winter, and dormancy must be released after spring freeze-thaw cycles.

In Ontario, Canada, sub-zero air and soil temperatures can occur for extended periods, consequently, cultivars must be winter hardy. Local trials of asparagus hybrids bred in different climatic zones indicated varying levels of adaptation (D.J. Wolyn, unpublished data). 'Guelph Millennium', bred in southern Ontario, is highly adapted with sustained high yields over many years. 'UC 157', developed in a mild California climate, usually dies after 3 to 4 years. 'Jersey Giant', bred in New Jersey, has moderate adaptation to southern Ontario and declines 3 to 4 years after establishment. The varied adaptation of these three cultivars could be related to different levels of winterhardiness.

The establishment of freezing tolerance in asparagus may be associated with physiological and biochemical changes including the production of cyroprotective compounds. Simple sugars such as sucrose and glucose can increase $\psi_{\mathrm{S}}$ to reduce ice formation and protect proteins from structural changes (Vagujfalvi et al., 1999); however, high and low

Received for publication 27 Aug. 2015. Accepted for publication 27 Oct. 2015. Funding was provided by the Asparagus Farmers of Ontario, the Agricultural Adaptation Council, and the Ontario Ministry of Agriculture, Food and Rural Affairs.

${ }^{1}$ Corresponding author. E-mail: dwolyn@uoguelph.ca. sucrose concentrations in asparagus rhizomes and buds can indicate growth and dormancy, respectively (Pressman et al., 1993). Fructans have a role in producing high $\psi_{\mathrm{S}}$ (Livingston, 1996) and can also maintain cellular integrity by binding membranes to keep them flexible and unimpaired during freezing (Cairns, 1992; Valluru and Van den Ende, 2008). Proline can protect cell membranes from desiccation (Kishor et al., 1995) and stabilize proteins (Verbruggen and Hermans, 2008). Expression of cold-regulated and antifreeze proteins and antioxidant enzymes can also increase protein concentrations with the acquisition of freezing tolerance (Herman et al., 2006; Patton et al., 2007; Zhang and Ervin, 2008). Increasing solute concentrations in the cell can depress freezing point and limit water availability for ice formation (Fujikawa et al., 1999; Guy, 2003).

Analysis of fall acclimation suggested GM asparagus had greater freezing tolerance than JG due to its early senescence and decreased percentage water, increased low-molecularweight nonstructural carbohydrate concentration, and decreased sucrose concentration in the rhizome (Landry and Wolyn, 2011). For a seedling experiment in controlled environments, where cold acclimation induced early senescence of GM as observed in the field, this cultivar had lower $\mathrm{LT}_{50}$ values (increased freezing tolerance) compared with JG after subfreezing acclimation, which was associated with high proline levels in crowns (Landry and Wolyn, 2012). In a subsequent analysis of seedling freezing tolerance, both cold acclimation and cold acclimation followed by subfreezing acclimation differentiated the three cultivars as predicted based on field adaptation (Kim and Wolyn, 2015). GM, JG, and UC had the 
lowest, moderate, and highest $\mathrm{LT}_{50}$ values, respectively. Freezing tolerance was associated with low percentage water and high proline, sucrose, and low- and high-molecular-weight fructan $(\mathrm{HF})$ concentrations in the crown. Analysis of $\mathrm{LT}_{50}$ during fall acclimation for the three cultivars in the field indicated that on specific sampling dates in early fall, GM crowns had greater freezing tolerance than those of UC, and values of JG were intermediate (Panjtandoust and Wolyn, 2016). Interestingly, all three cultivars had similar $\mathrm{LT}_{50}$ values at the start of winter.

Direct measurements of $\mathrm{LT}_{50}$ and associated physiological parameters among the asparagus cultivars during natural fall or artificial cold acclimation suggested that varying levels of freezing tolerance can explain differences in persistence and adaptation (Kim and Wolyn, 2015; Landry and Wolyn, 2012; Panjtandoust and Wolyn, 2016). However, the timing of deacclimation or dehardening in the spring may also be important for survival. The early release of dormancy and loss of freezing tolerance from increasing temperatures could make asparagus plants susceptible to damage from late freeze-thaw cycles and result in low winterhardiness and poor adaptation, as observed in alfalfa (Medicago sativa), another herbaceous perennial (Suzuki, 1981), and grasses (Hoffman et al., 2014; Jørgensen et al., 2010).

Genetic variation for the minimum temperature at which dormant asparagus buds begin to grow has been demonstrated in controlled environments ( $\mathrm{Ku}$ et al., 2007). Since values for $\mathrm{JG}$ and $\mathrm{UC}$ were 12.5 and $10{ }^{\circ} \mathrm{C}$, respectively, one can hypothesize that UC releases dormancy and loses freezing tolerance earlier than JG and is more susceptible to frost damage from spring freeze-thaw cycles.

The identification of three asparagus cultivars, GM, JG, and $\mathrm{UC}$, with varying levels of adaptation to the cold climate of southern Ontario allows detailed investigations into how release of dormancy and loss of freezing tolerance in the spring may affect winterhardiness. The objectives of this research were to assess freezing tolerance and associated biochemical and physiological parameters of these three cultivars under field conditions during the spring. The differing spring climates over the 2 years of this experiment, where soil temperatures increased unusually early then decreased in year 1 , and increased later than normal in year 2 , offered insight into genetic variation for deacclimation and its role in adaptation of asparagus cultivars to cold temperate regions.

\section{Materials and Methods}

Plant establishment. Seed for cultivars JG and UC were obtained from Jersey Asparagus Farms, Pittsgrove, NJ, and those for GM were obtained from the Ontario Asparagus Growers Marketing Board, Simcoe, ON, Canada. Cultivars are full-sib families derived by crossing two heterozygous parents. Seeds were sown into 288-cell plug trays with potting mix (Sunshine LC 4; Sun Gro Horticulture Canada, Seba Beach, AB, Canada) on 4 Mar. 2011 and 20 Mar. 2012. Young seedlings were transplanted to 50-cell plug trays containing soilless potting mix (Sunshine LC 1; Sun Gro Horticulture Canada) after 4 weeks, fertigated weekly with $1.25 \mathrm{~g} \cdot \mathrm{L}^{-1} 20 \mathrm{~N}-$ 3.5P-16.6K (Plant Products Limited, Brampton, ON, Canada) and grown in the greenhouse at $25 / 20{ }^{\circ} \mathrm{C}$ (day/night) under natural light with a supplemental 12 -h photoperiod provided by high-pressure sodium lamps.

Seedlings for the three cultivars were transplanted to the field at the Simcoe Research Station, Simcoe, ON, Canada (lat. $42^{\circ} 51^{\prime} \mathrm{N}$, long. $80^{\circ} 16^{\prime} \mathrm{W}$, elevation $240.5 \mathrm{~m}$ ) on 20 May 2011 and 28 May 2012 into Brookton sandy clay loam and Renton sandy loam soils, respectively. The experiment in each year was conducted as a balanced split-plot design with sampling dates as main plots and cultivars as subplots. Main plots were organized in four replicates using a randomized complete block design. Subplots consisted of 35 crowns spaced $30 \mathrm{~cm}$ within a row and $1.25 \mathrm{~m}$ between each row. Plants were fertilized $\left(50 \mathrm{~kg} \cdot \mathrm{ha}^{-1} 10 \mathrm{~N}-4.4 \mathrm{P}-8.3 \mathrm{~K}\right)$ in both years. Manual weed removal and inter-row application of glyphosate (Roundup;

Table 1. Significance of fixed effects $(P \leq 0.05)$ from the restricted maximum likelihood covariance parameter estimates for three asparagus cultivars harvested on four spring sampling dates in 2012 and 2013 at the Simcoe Research Station, Simcoe, ON, Canada.

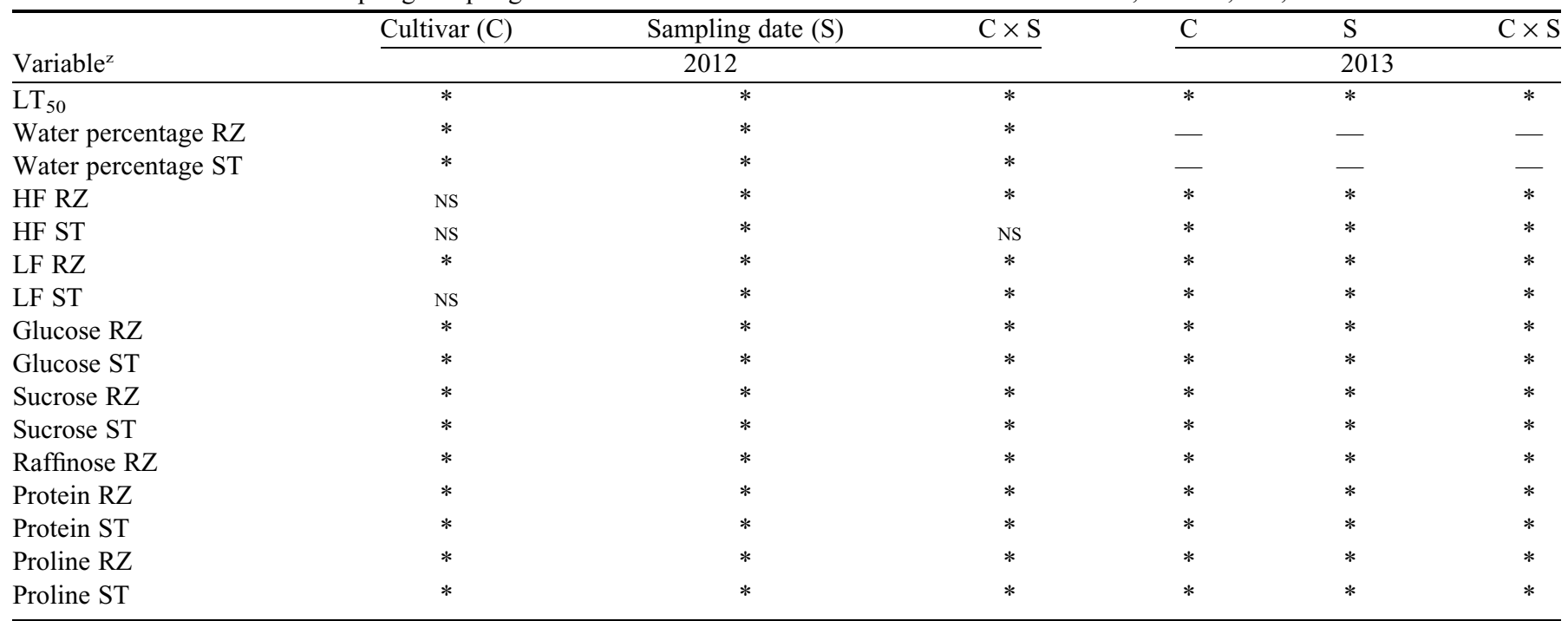

${ }^{\mathrm{z}} \mathrm{ST}=$ storage root, $\mathrm{RZ}=$ rhizome, $\mathrm{HF}=$ high-molecular-weight fructan, $\mathrm{LF}=$ low-molecular-weight fructan.

Ns, *Nonsignificant or significant at $P \leq 0.05$, respectively. 
Monsanto, St. Louis, MO) at a concentration of $360 \mathrm{~g} \cdot \mathrm{L}^{-1}$ were used as needed. Agronomic practices were applied as recommended (Ontario Ministry of Agriculture and Food, 2004).

SAMPLE HARVESTS. The main plots were sampled in Spring 2012 and 2013 on four dates in each year. The first sampling commenced with the thawing of ground in the late winter or early spring. Plots planted in 2011 were sampled in 2012 on 14 Mar., 22 Mar., 26 Mar., and 4 Apr. and those planted in 2012 were sampled in 2013 on 4 Apr., 9 Apr., 17 Apr., and 21 Apr. On each of the sampling dates, 35 crowns from each subplot were dug and cleaned of soil. Ten of the 35 crowns were separated into rhizomes and storage roots and stored at $4{ }^{\circ} \mathrm{C}$ until further processing. Rhizomes and storage roots from five plants were lyophilized and used to assess water percentage according to Tanino et al. (1990). Water percentage of rhizomes and storage roots could only be measured in 2012 due to small crown size in 2013. For the remaining five crowns, bud scales and epidermal tissues of rhizomes were removed, and rhizomes and storage roots were frozen separately in liquid nitrogen, stored at $-80{ }^{\circ} \mathrm{C}$, then lyophilized (FreeZone 4.5L Freeze Dry System, model 77510; Labconco, Kansas City, MO). Bulked storage root and rhizome samples were ground in a blender (1 L Standard Laboratory Blender; Waring Laboratory Science, Stamford, CT) until the powder could pass a 60 -mesh sieve and stored at $-80^{\circ} \mathrm{C}$.

$\mathbf{L T}_{\mathbf{5 0}}$ ASSESSMENT. The 25 crowns from each subplot were trimmed, such that storage roots were $20 \mathrm{~cm}$ in length, and planted individually into pots $(17 \mathrm{~cm}$ diameter $\times 22 \mathrm{~cm}$ deep) with bark mix ( $70 \%$ aged pine bark fines, $25 \%$ peatmoss, $5 \%$ compost; ASB Greenworld, Mount Elgin, ON, Canada), which served to simulate the soil environment and initiate ice nucleation during freezing treatments. Potted crowns were watered and stored at $4{ }^{\circ} \mathrm{C}$ for $12 \mathrm{~h}$. After the chilling period, five pots from each field replicate for each of the three cultivars were distributed randomly in each of four chest freezers. The five remaining pots from each plot served as controls and were stored at $4{ }^{\circ} \mathrm{C}$ for $24 \mathrm{~h}$, then regrown in the greenhouse. Potted crowns in the chest freezers were chilled at $4{ }^{\circ} \mathrm{C}$ for $24 \mathrm{~h}$, then freezing treatments of $0,-6,-12$, and $-18{ }^{\circ} \mathrm{C}$ were achieved by decreasing the temperature by $3{ }^{\circ} \mathrm{C} \cdot \mathrm{h}^{-1}$. After the desired freezing temperature was achieved, it was held constant for $12 \mathrm{~h}$, then five random pots of each cultivar were removed from each replicate freezer, after which the temperature decreased to the next treatment level. Controls and pots from two chest freezers were placed in one greenhouse and those from the remaining two chest freezers were placed in a separate replicate greenhouse. Plants were grown for 3 weeks at $20 / 15{ }^{\circ} \mathrm{C}$ (day/night) with natural light supplement with a 16-h photoperiod provided by highpressure sodium lamps. Individual crowns with at least one vigorous spear were classified as surviving the freezing treatment.

Metabolite analysis. Carbohydrate concentrations were determined using commercial analysis kits (K-FRUC and K-RAFGL; Megazyme International Ireland, Bray, Ireland) according to Landry and Wolyn (2011) with one modification for simple carbohydrate estimates: at the start of the analysis, the rhizome and storage root samples were incubated with $5 \mathrm{~mL}$ of $95 \%(\mathrm{v} / \mathrm{v})$ ethanol at room temperature to inactivate endogenous enzymes. Proline was quantified with ninhydrin (Landry and Wolyn, 2011).

To measure protein concentration, freeze-dried tissue $(100 \mathrm{mg})$ was homogenized in $1 \mathrm{~mL}$ of chilled $0.1 \mathrm{~mm}$ Tris-hydrochloric
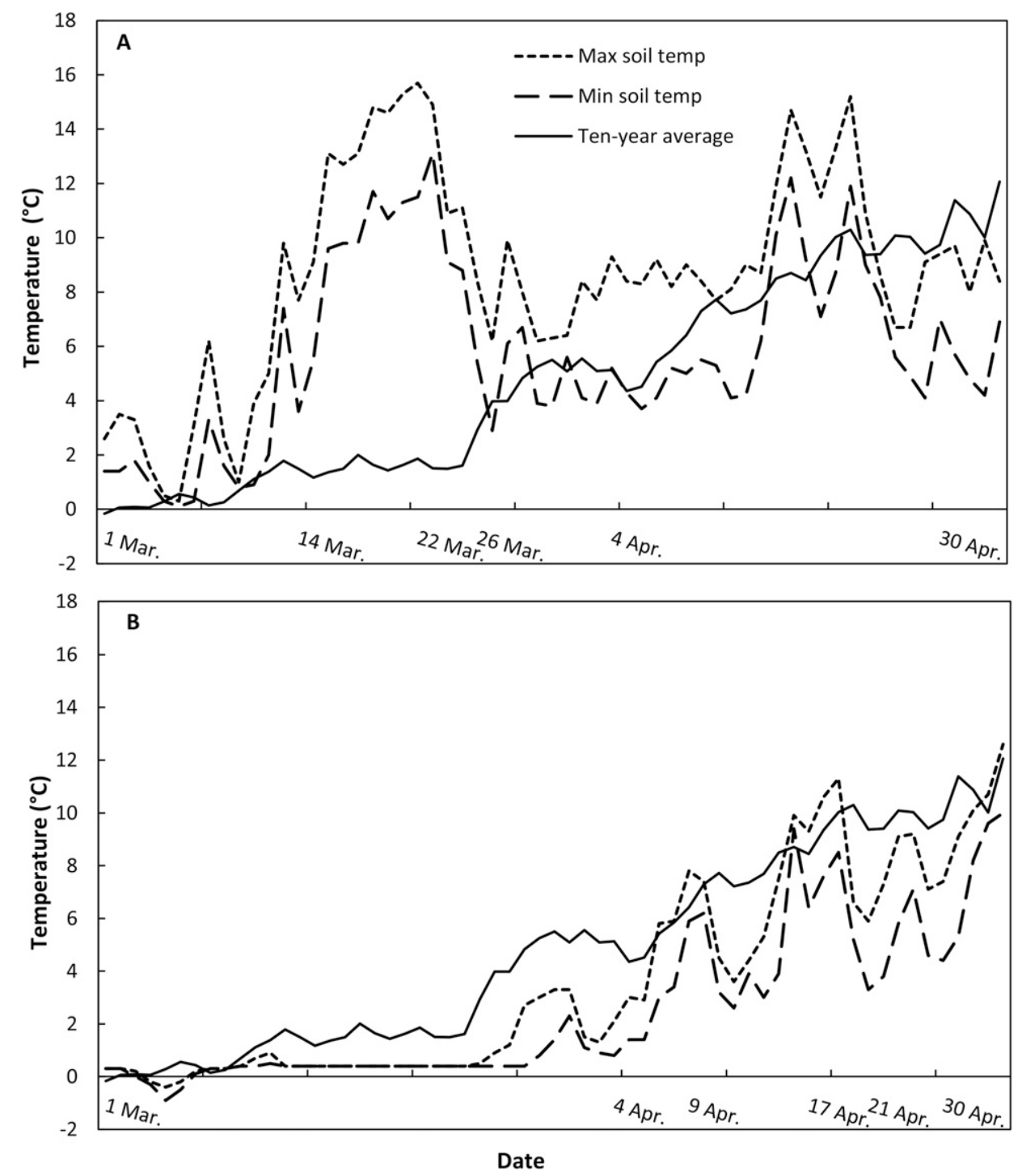

Fig. 1. Daily minimum and maximum soil temperatures at $10 \mathrm{~cm}$ during Spring (A) 2012 and (B) 2013, and the 10-year average, at the Simcoe Research Station, Simcoe, ON, Canada. Temperatures from 1 Mar. to 30 Apr. are shown and intervals between tick marks represent $7 \mathrm{~d}$; the remaining dates indicate when sampling occurred. 

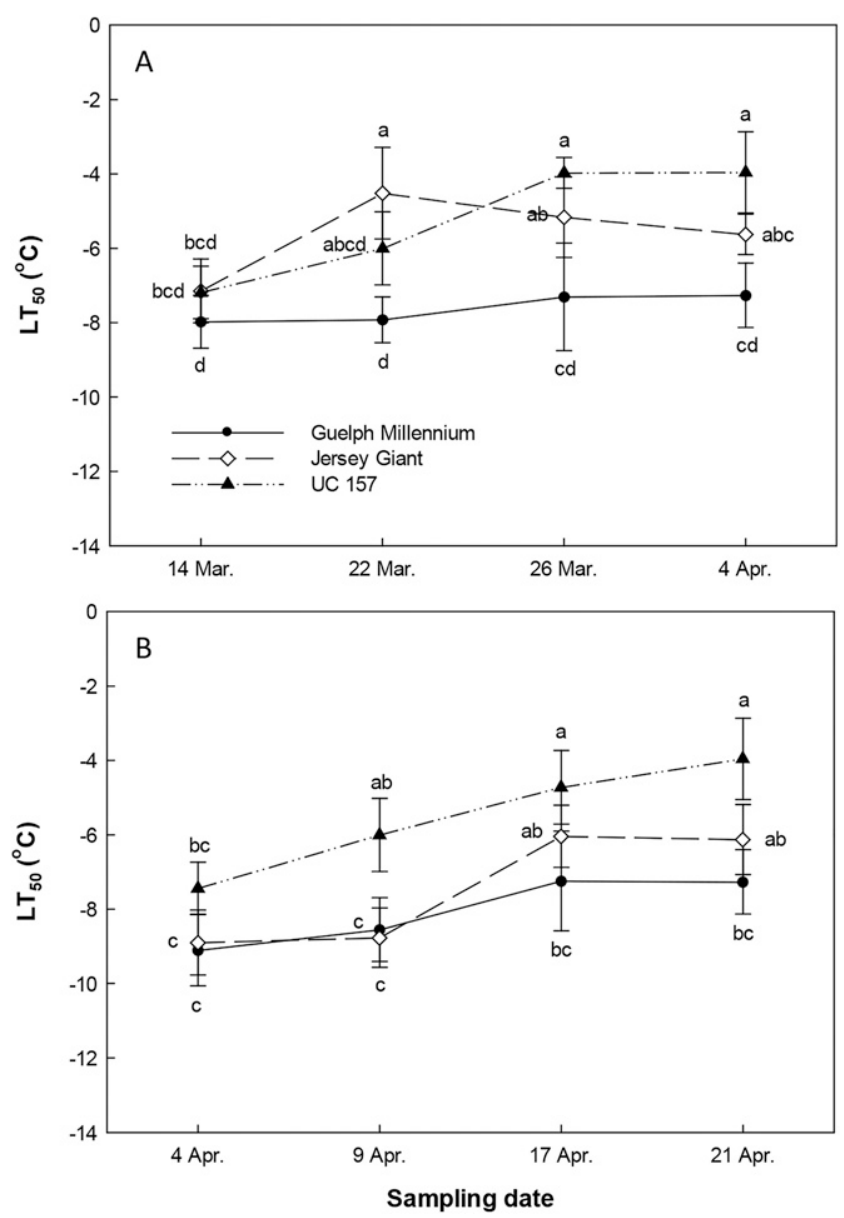

Fig. 2. $\mathrm{LT}_{50}$ values, the temperature at which $50 \%$ of plants die, for three asparagus cultivars evaluated in Spring (A) 2012 and (B) 2013 at the Simcoe Research Station, Simcoe, ON, Canada. Vertical error bars represent the SE at each sampling date $(n=4)$. Letters represent significant differences as determined by Tukey's honestly significant difference $(P \leq 0.05)$. acid buffer ( $\mathrm{pH} 7.5)$. The homogenate was centrifuged at $12,000 g_{\mathrm{n}}$ for $20 \mathrm{~min}$ at $4{ }^{\circ} \mathrm{C}$. The total protein concentration of the homogenate was determined according to Bradford (1976) using a spectrophotometer (model DU-64; Beckman, Fullerton, $\mathrm{CA}$ ) and bovine serum albumin as the standard.

STATISTICAL ANalysis. Residuals were tested for normality by the Shapiro-Wilk test and for the homogeneity of variances by univariate procedures (SAS version 9.3; SAS Institute, Cary, $\mathrm{NC}$ ); no transformations were necessary. Restricted maximum likelihood covariance parameter estimates were performed on $\mathrm{LT}_{50}$ values and physiological and biochemical parameters using PROC MIXED (SAS version 9.3). Means were separated using Tukey's honestly significant difference $(P \leq 0.05)$. Pearson correlation coefficients were calculated between $\mathrm{LT}_{50}$ and physiological and biochemical parameters using PROC CORR. $\mathrm{LT}_{50}$ values were estimated with probit analysis of the number of surviving crowns at each temperature using PROC PROBIT and the OPTC option.

\section{Results}

Statistical analysis. From the analysis of variance, the random effects of year and its interaction with the fixed effects of cultivar, sampling date, and cultivar $\times$ sampling date were significant for all parameters; therefore, years were analyzed separately. The significance of fixed effects and their interactions in each year are summarized (Table 1). For most traits in both years the cultivar $\times$ sampling date interactions were significant.

Seasonal temperature profiles. The spring seasons of 2012 and 2013 were distinct and offered a unique opportunity to study deacclimation and freezing tolerance. In 2012, March was unseasonably warm and soil temperatures increased rapidly from 0 to $16 / 14{ }^{\circ} \mathrm{C}$ (maximum/minimum), then decreased and stabilized to $\approx 8 / 6^{\circ} \mathrm{C}$ (Fig. 1A). Plots were sampled: 1) at the beginning of the temperature increase, 2) at the maximum temperature, 3) after soil temperature
Rhizome

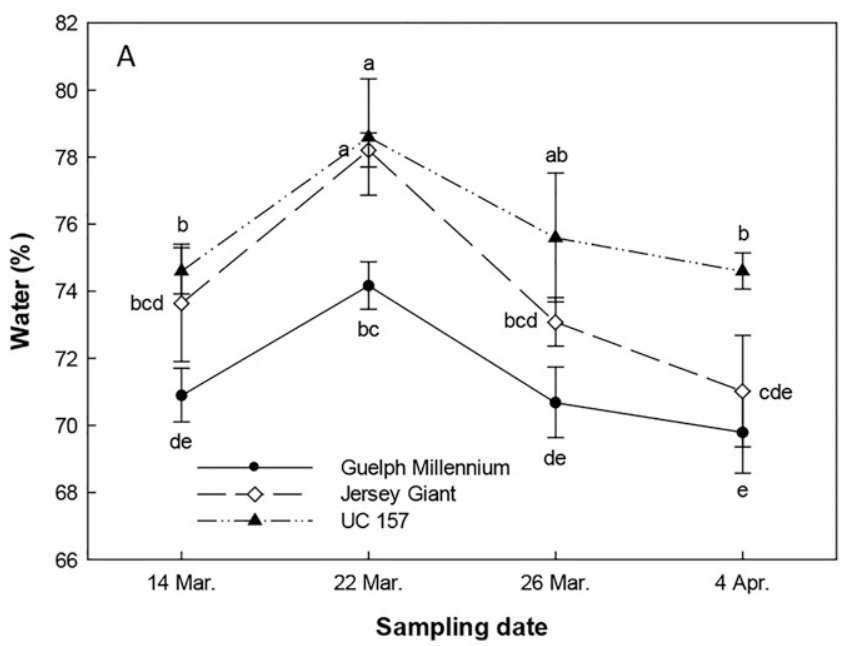

Storage root

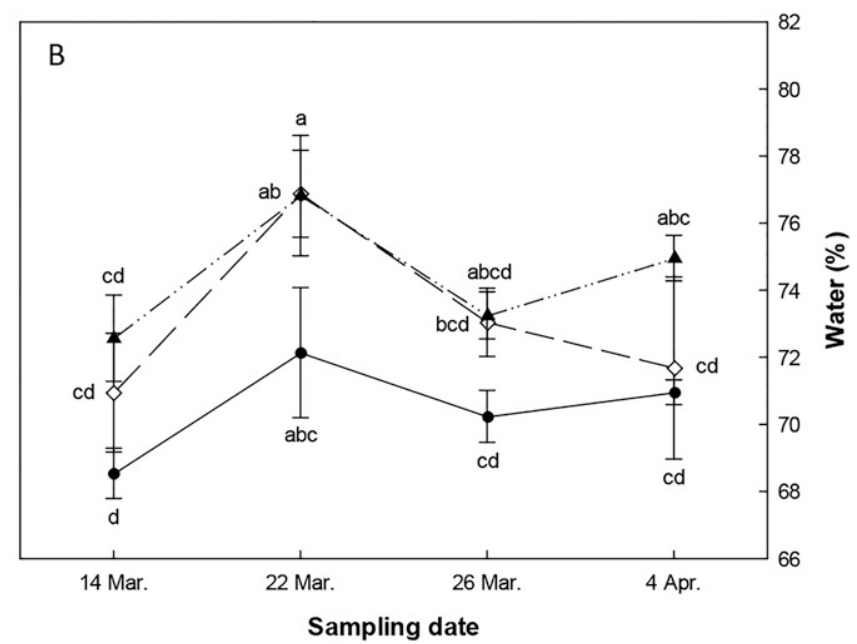

Fig. 3. (A) Rhizome and (B) storage root water percentage for three asparagus cultivars evaluated in Spring 2012 at the Simcoe Research Station, Simcoe, ON, Canada. Vertical error bars represent the SE at each sampling date $(n=4)$. Letters indicate significant differences determined by Tukey's honestly significant difference $(P \leq 0.05)$. 
declined, and 4) 1 week after the decline when temperatures were stable.

In 2013, March was unseasonably cold with soil temperatures consistently near $1{ }^{\circ} \mathrm{C}$ (Fig. 1B). Temperatures rose in April when sampling occurred. Despite weekly fluctuations, values increased gradually from the first to the fourth sampling date.

$\mathbf{L T}_{\mathbf{5 0}} \cdot \mathrm{LT}_{50}$ values increased (freezing tolerance decreased) over the sampling period for UC, but remained unchanged for GM in 2012 and 2013 (Fig. 2). Cultivars did not differ on the first sampling dates, but UC had higher values than GM on the final dates in both years. For JG, $\mathrm{LT}_{50}$ increased from the first to the second sampling date in 2012, coinciding with the rapid, early increase in soil temperature, then appeared to decline. Both UC and GM did not respond during this same period. In 2013, $\mathrm{LT}_{50}$ for JG increased between the second and third sampling dates in April, but values did not differ from those of GM.

Water Percentage. Rhizome water percentage increased from the first to the second sampling date for all cultivars in 2012, then decreased to the final date (Fig. 3A). The response reflected the increasing, then decreasing, soil temperatures. UC had higher water percentage than GM on all sampling dates and
JG had intermediate values, not differing from both cultivars on most dates except for the second, when values were similar to those of UC and greater than those of GM. Cultivars did not differ for storage root water percentage over the sampling period in 2012 (Fig. 3B); however, values increased for all cultivars from the first to the second sampling date, coincident with the early seasonal increase in temperature. Data for 2013 were not obtained.

Fructans. In 2012, rhizome HF concentrations increased over the sampling period only for UC and cultivars did not differ on each date (Fig. 4A). Storage root HF concentrations did not vary over dates or among cultivars (Fig. 4B).

Rhizome HF concentrations decreased in 2013 over the first three sampling dates only for UC; values for GM and JG did not change over time and cultivars did not differ on any sampling date (Fig. 4C). Storage root HF decreased in all cultivars over the sampling period; values for GM were greater than those for UC and JG at the latter two sampling dates when UC and JG did not differ (Fig. 4D). For both years, HF concentrations in storage roots were about double than those in the rhizome.

LF concentrations varied distinctly between years and crown organs: storage root and rhizome (Fig. 5A-D). In
Rhizome
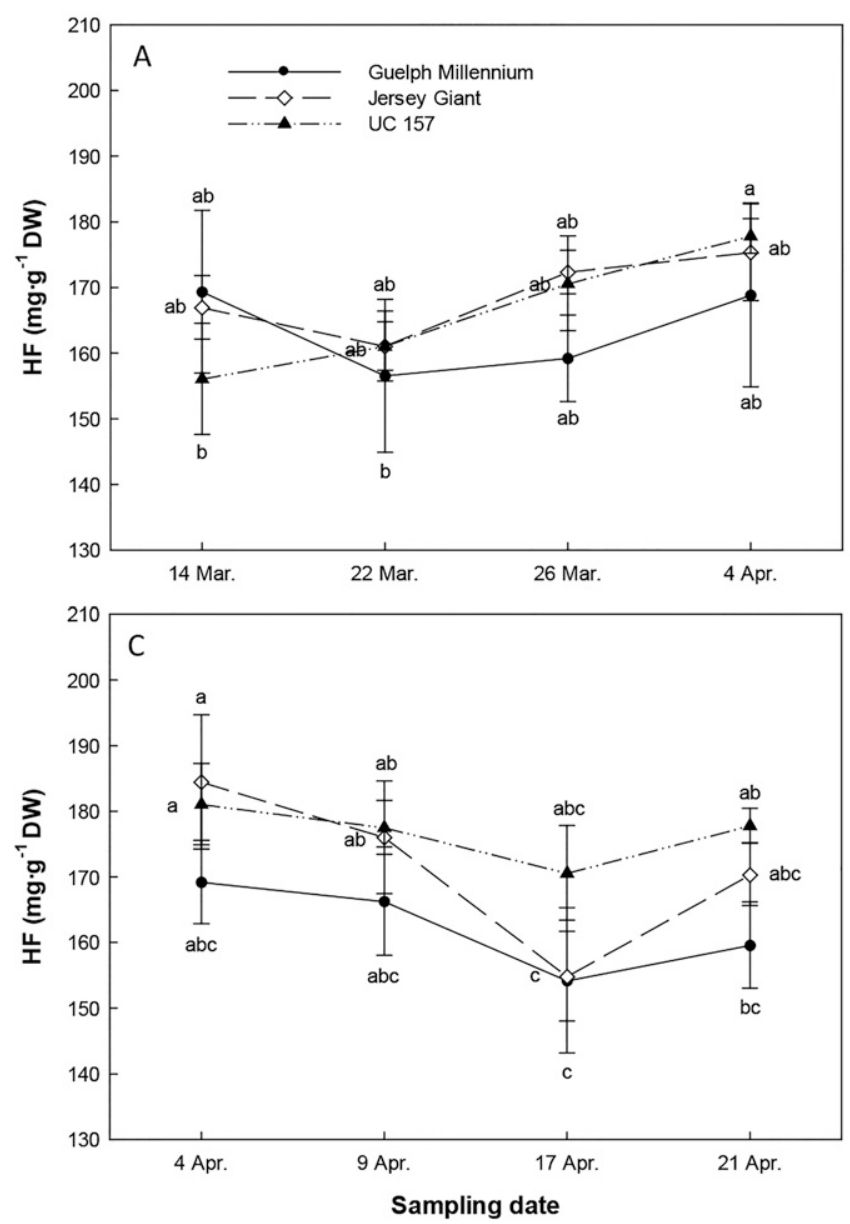

Storage root
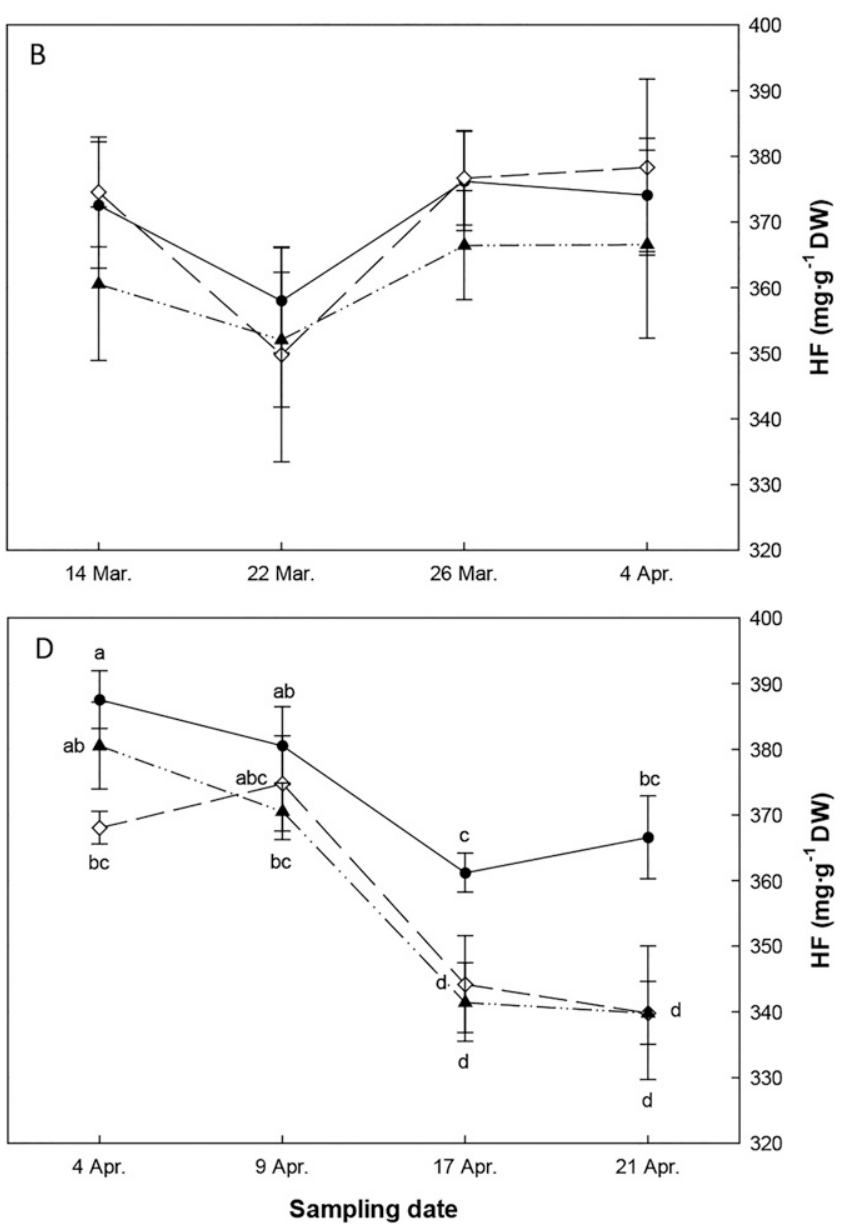

Fig. 4. (A, C) Rhizome and (B, D) storage root high-molecular-weight fructan (HF) concentrations for three asparagus cultivars evaluated in Spring (A, B) 2012 and (C, D) 2013 at the Simcoe Research Station, Simcoe, ON, Canada. Vertical error bars represent the SE at each sampling date $(n=4)$. Letters indicate significant differences determined by Tukey's honestly significant difference $(P \leq 0.05)$. 

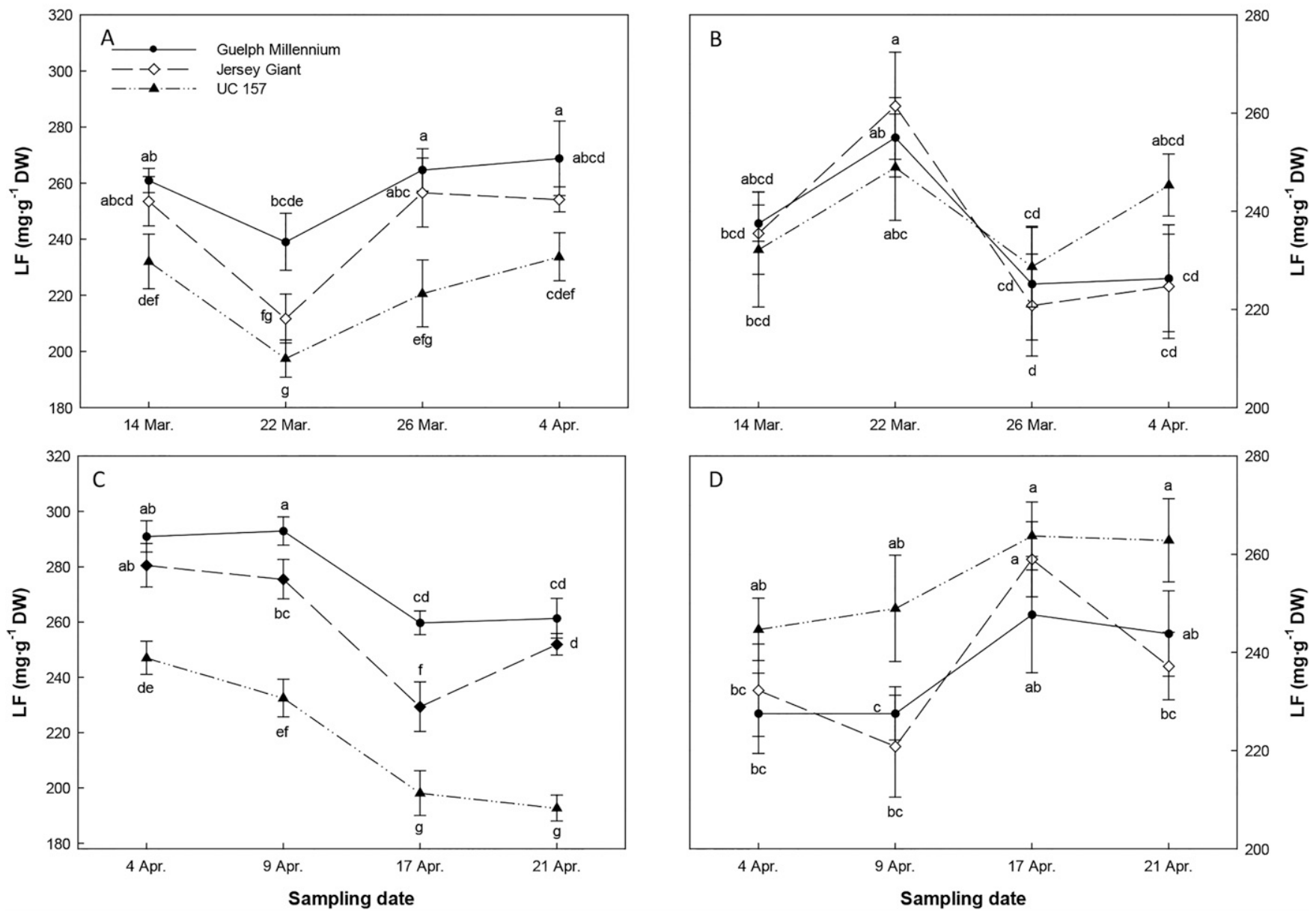

Fig. 5. (A, C) Rhizome and (B, D) storage root low-molecular-weight fructan (LF) concentrations for three asparagus cultivars evaluated in Spring (A, B) 2012 and (C, D) 2013 at the Simcoe Research Station, Simcoe, ON, Canada. Vertical error bars represent the SE at each sampling date $(n=4)$. Letters indicate significant differences determined by Tukey's honestly significant difference $(P \leq 0.05)$.

2012, rhizome LF generally decreased, then increased, coincident with increases and decreases in soil temperature, respectively (Fig. 5A). GM had greater rhizome LF concentrations at all sampling dates compared with UC; the concentration for JG was similar to that of UC on the second sampling date, when soil temperature was greatest, but similar to that of GM on the third sampling date after soil temperature decreased. Consequently, JG appeared most responsive to changing soil temperatures, deacclimating and reacclimating to a greater degree than the other two cultivars. Patterns for changing storage root LF concentrations over the sampling period in 2012 were generally opposite to those observed for the rhizome (Fig. 5B), although concentrations decreased only for GM and JG from the second to third sampling date.

In 2013, rhizome LF concentrations generally decreased over the sampling period as temperatures increased and both GM and JG had greater values on each date than UC (Fig. 5C). Rhizome LF was greater for GM than JG only on the second and third sampling dates. Storage root LF concentrations (Fig. 5D) were generally opposite to those observed for rhizome; values for UC were greater than those for GM on most sampling dates and concentrations decreased as the season progressed in a limited number of comparisons.
SuCrose. Sucrose concentrations varied distinctly over the sampling periods between years and crown organs (Fig. 6A-D). In 2012, rhizome sucrose concentrations generally increased, then decreased (Fig. 6A), similar to the soil temperature profile. Values for UC were greater than those for GM on most sampling dates. Concentrations for JG were similar to those of UC and differed from those of GM on the second and third sampling dates. For storage roots, sucrose concentrations decreased from the first to the second or third sampling date, and the values remained stable thereafter (Fig. 6B). For the latter two sampling dates, sucrose concentrations were greater for GM than UC and those for JG were intermediate and did not differ from values of the other cultivars.

In 2013, rhizome sucrose concentrations increased over the sampling period for all cultivars and levels for UC were greater than those for GM; values for JG were intermediate to those of GM and UC on the first two sampling dates but similar to those of GM on the latter two sampling dates (Fig. 6C). Storage root sucrose concentrations decreased over the sampling period and values for GM were greater than those for UC on most dates (Fig. 6D). JG did not differ from UC and GM on most sampling dates. Sucrose levels of rhizomes were three to five times those in storage roots in both years. 

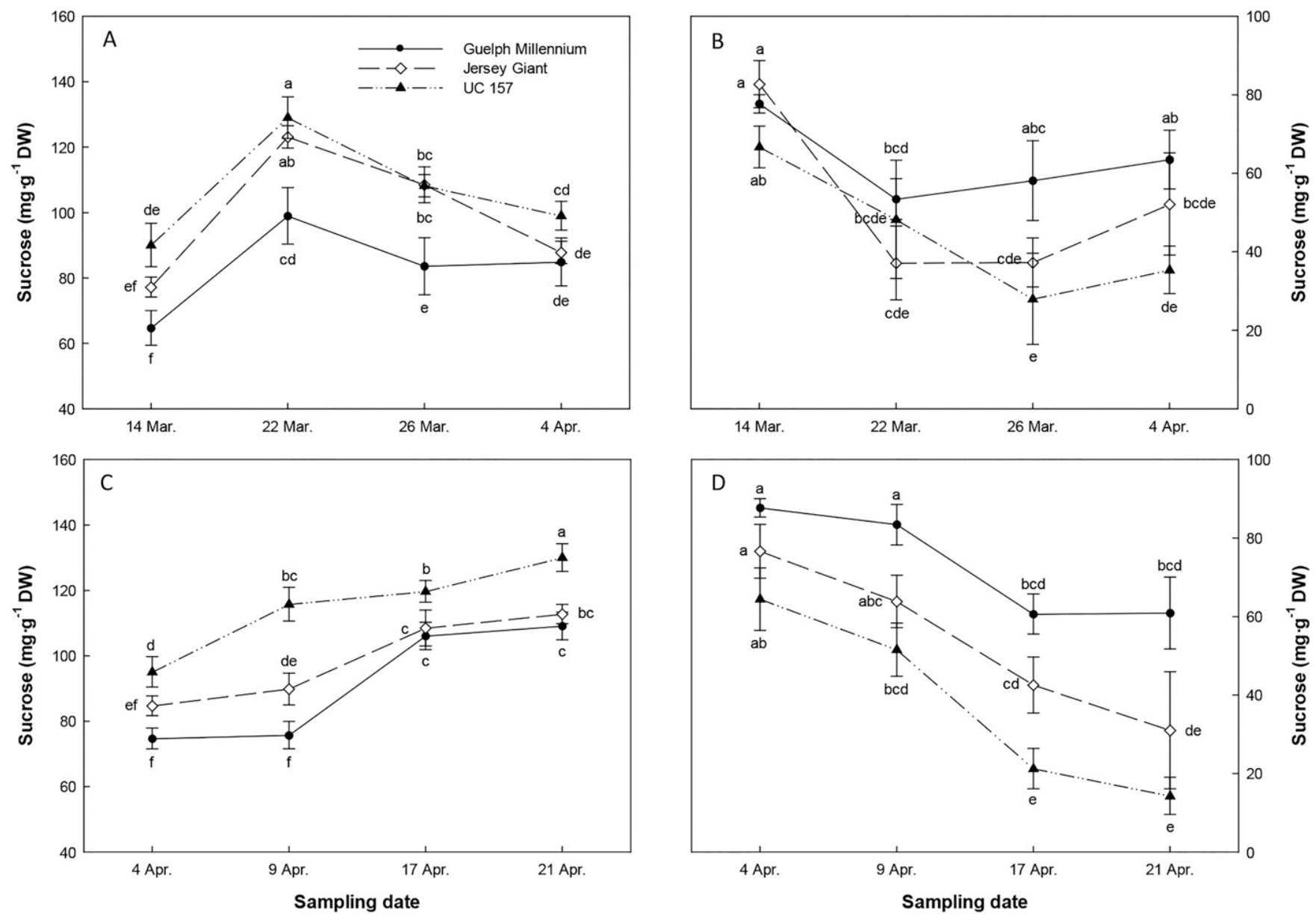

Fig. 6. (A, C) Rhizome and (B, D) storage root sucrose concentrations for three asparagus cultivars evaluated in Spring (A, B) 2012 and (C, D) 2013 at the Simcoe Research Station, Simcoe, ON, Canada. Vertical error bars represent the sE at each sampling date $(n=4)$. Letters indicate significant differences determined by Tukey's honestly significant difference $(P \leq 0.05)$.

RAFFINOSE. In 2012, rhizome raffinose concentrations decreased from the first to the second sampling date for all cultivars, then increased or remained unchanged for subsequent dates (Fig. 7A). UC had less rhizome raffinose than both GM and JG on two sampling dates and GM and JG did not differ on any date. Rhizome raffinose concentrations decreased between the second and third sampling dates in 2013 and values for GM were greater than those for UC for the latter two sampling dates (Fig. 7B). JG did not differ from GM and $\mathrm{UC}$ expect for the third sampling date when it differed from GM.

GLuCose. Changing patterns of glucose concentrations over the sampling periods differed between years and for crown organs (Fig. 8A-D). In 2012, rhizome glucose concentrations decreased and increased from the first to the third sampling dates (Fig. 8A). Thereafter, concentrations did not change for UC and JG, but decreased for GM. Values were greater for GM than UC on the second, third and fourth sampling dates. For JG, levels were similar to those of UC on the second and third sampling dates and similar to that for GM on the fourth date. Storage root glucose concentrations increased for all cultivars from the first to the second sampling date, then decreased from the second to third, and did not change thereafter (Fig. 8B). Cultivars did not differ at all sampling dates except for the third, when the value for GM was greater than those for UC and JG.

In 2013, rhizome glucose concentrations generally decreased from the first to the third sampling date, then did not change (Fig. 8C). Cultivars did not differ on most sampling dates. Storage root glucose concentration increased for all cultivars between the second and third sampling dates and did not change thereafter for GM and JG, but increased for UC (Fig. 8D). Values for UC were generally greater than those for GM across sampling dates. JG differed from UC and GM on distinct dates.

Proline. Changing patterns of proline concentrations over the sampling period were similar for both rhizomes and storage roots in 2012 (Fig. 9A and B). Values decreased from the first to the second date, increased from the second to the third, then did not change. GM generally had greater proline concentrations than UC in both storage roots and rhizomes over the sampling period. For JG, rhizome proline concentrations decreased from the first to second sampling date when values were lower than those of GM but increased from the second to third sampling when values were similar to those of GM but differed from those of UC. 
Rhizome
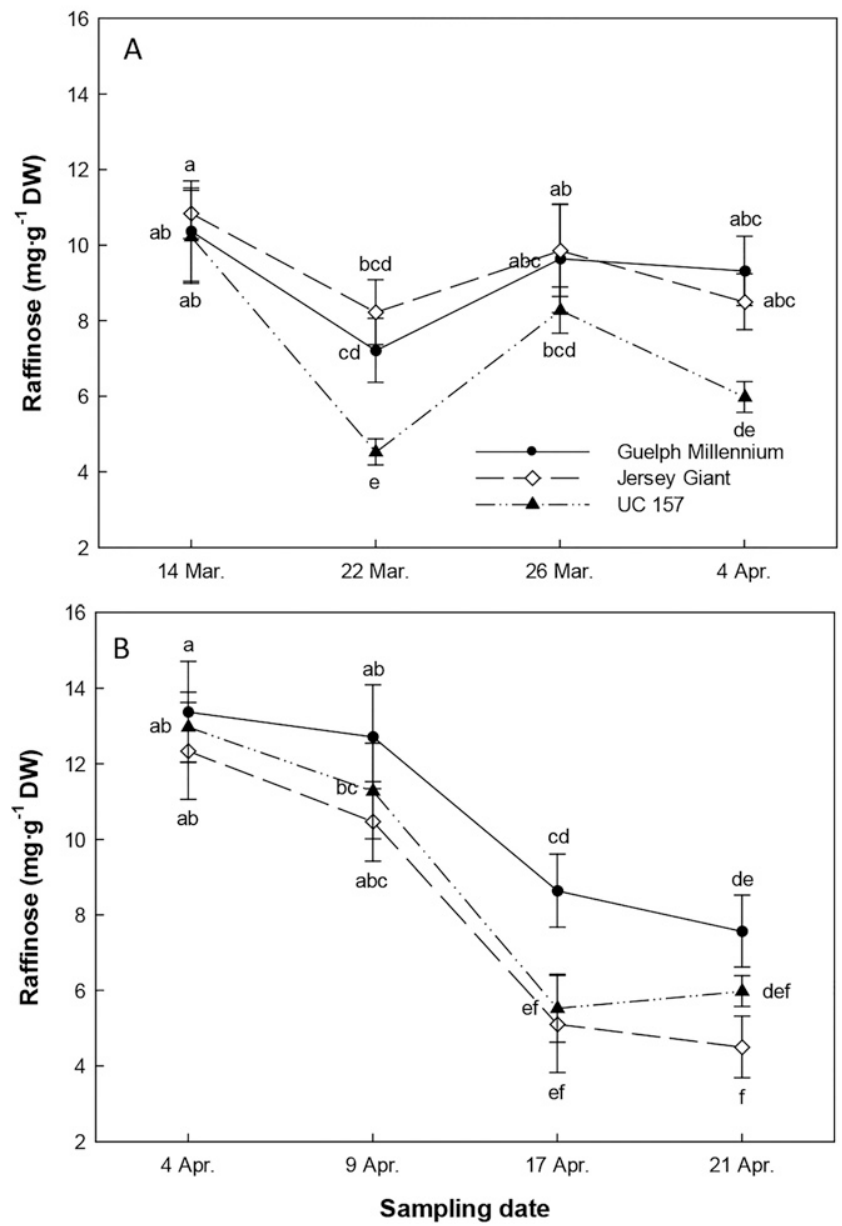

Fig. 7. Rhizome raffinose concentrations for three asparagus cultivars evaluated in Spring (A) 2012 and (B) 2013 at the Simcoe Research Station, Simcoe, ON, Canada. Vertical error bars represent the SE at each sampling date $(n=4)$. Letters indicate significant differences determined by Tukey's honestly significant difference $(P \leq 0.05)$.

In 2013, rhizome and storage root proline concentrations decreased between the second and third sampling dates (Fig. 9C and D). JG rhizome proline concentrations were greater than those for UC at the third and fourth sampling dates (Fig. 9C). Both GM and JG storage root proline concentrations were greater than those for UC on the third and fourth sampling dates.

Protein. Changing patterns of protein concentrations over the sampling periods differed between years in both rhizomes and storage roots (Fig. 10A and D). For rhizome protein concentrations in 2012, values for JG decreased from the first to the second sampling date, then increased from the second to third date (Fig. 10A). Concentrations for GM and UC increased after the second sampling date. Values for GM were generally greater than those for $\mathrm{UC}$ and $\mathrm{JG}$; JG rhizome protein concentrations differed from those of GM on the second sampling date but were similar to those of GM and UC on the third and fourth dates. Storage root protein concentrations generally did not change over the sampling period (Fig. 10B).

In 2013, rhizome protein concentrations decreased between the second and third sampling dates, then did not change (Fig. 10C). Values for GM were greater than those for UC. JG was similar to GM on all sampling dates. Storage root protein concentrations generally did not differ over sampling dates or between cultivars (Fig. 10D). Protein levels were three to four times greater in the rhizome than the storage root.

Correlations. Low $\mathrm{LT}_{50}$ values (high freezing tolerance) were correlated with high LF and low sucrose concentrations in rhizomes, and high proline concentration in storage roots on two or more sampling dates in both years (Table 2). Freezing tolerance was also associated with high rhizome glucose and proline concentrations and low water percentage on three or more sampling dates in 2012.

\section{Discussion}

The study of deacclimation over two distinct spring seasons for three asparagus cultivars with varying survival in southern Ontario provided new insights into winterhardiness and adaptation. The early temperature increase in Mar. 2012, followed by a period of cold, contrasted with the late increasing temperatures in Apr. 2013, allowed the discrimination of cultivars for both deacclimation and reacclimation. Although cultivars did not differ for $\mathrm{LT}_{50}$ as temperatures began to rise above freezing each year, values at the end of the sampling period were consistent with adaptation: $\mathrm{GM}>\mathrm{JG}>\mathrm{UC}$. Concentrations of many compounds associated with freezing tolerance changed in conjunction with temperature, increasing then decreasing, or vice versa, in 2012, and steadily changing, increasing or decreasing, in 2013; they also varied according to cultivar adaptation. Freezing tolerance during deacclimation was most associated with rhizome traits: high LF, glucose, and proline concentrations, low sucrose concentration, and low water percentage. High proline concentration in storage roots was also correlated with freezing tolerance.

Carbohydrate concentrations in rhizomes and/or storage roots varied during the deacclimation period and among cultivars. Values for raffinose and glucose were low, less than $20 \mathrm{mg} \cdot \mathrm{g}^{-1}$ dry weight (DW), in comparison with HF in storage roots, $340-380 \mathrm{mg} \cdot \mathrm{g}^{-1} \mathrm{DW}$, and LF in rhizomes, $200-$ $300 \mathrm{mg} \cdot \mathrm{g}^{-1} \mathrm{DW}$. The contributions of the former two compounds to freezing tolerance, especially considering the effects of solute concentration on freezing point and water availability for ice crystallization, may be minimal; however, the molar concentrations of raffinose and glucose could be contributing somewhat to freezing tolerance by protecting cellular components.

The ranking of $\mathrm{LT}_{50}$ values for three cultivars at the end of the spring sampling period in both years, $\mathrm{GM}<\mathrm{JG}<\mathrm{UC}$, is consistent with observations from cold acclimation of seedlings in controlled environments (Kim and Wolyn, 2015; Landry and Wolyn, 2012) and early fall acclimation of crowns in the field (Panjtandoust and Wolyn, 2016). Thus, fall and spring freezing tolerance is correlated in these three genotypes. Cultivars differed for $\mathrm{LT}_{50}$ values at early fall samplings with values for GM lower than those for UC; however, they did not differ in late fall (Panjtandoust and Wolyn, 2016). Conversely, the two cultivars did not differ for the early spring sampling dates but did differ at the final sampling dates in this study. GM may have a higher minimum temperature for both the induction and release of dormancy than $\mathrm{UC}$, resulting in early acquisition and 

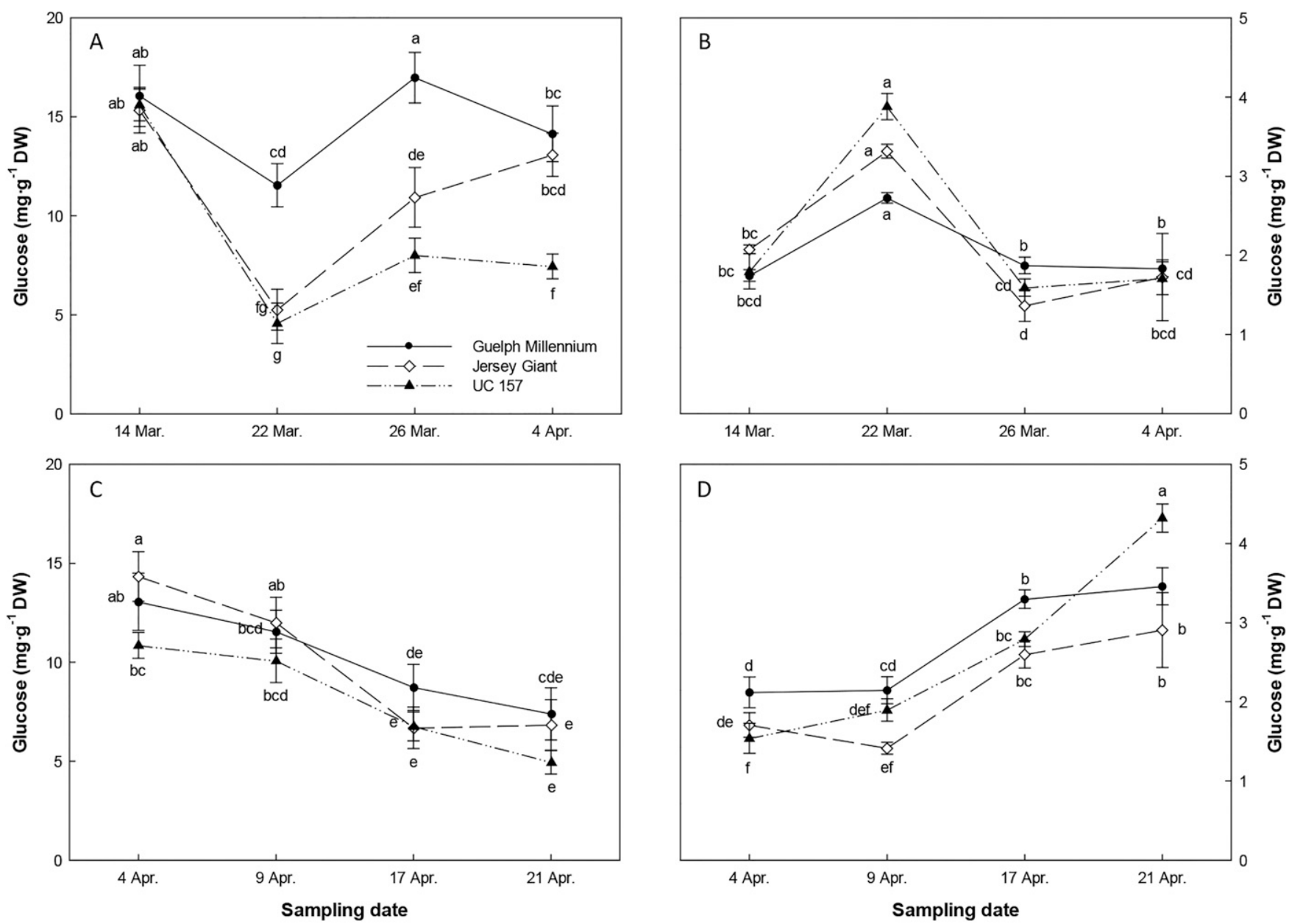

Fig. 8. (A, C) Rhizome and (B, D) storage root glucose concentrations for three asparagus cultivars evaluated in Spring (A, B) 2012 and (C, D) 2013 at the Simcoe Research Station, Simcoe, ON, Canada. Vertical error bars represent the SE at each sampling date $(n=4)$. Letters indicate significant differences determined by Tukey's honestly significant difference $(P \leq 0.05)$.

late loss of freezing tolerance in fall and spring, respectively. Similarly in cereals, threshold induction temperatures were related to freezing tolerance and the speed of hardening and dehardening (Sãulescu and Braun, 2001).

Asparagus cultivars can have differing chilling requirements for release of dormancy (Ku et al., 2007). GM often has delayed spring emergence in areas with milder winters than that observed in southern Ontario and could have a strong chilling requirement associated with dormancy release at high temperatures. In woody perennial plants, species with strong chilling requirements have higher cold tolerance and require higher spring temperatures to trigger the deacclimation process compared with those with a low chilling requirement (Arora et al., 2003).

The cultivars demonstrated three distinct patterns of deacclimation as indicated by $\mathrm{LT}_{50}$ measurements. Values for $\mathrm{UC}$ increased over time and were unaffected by fluctuations in soil temperatures, suggesting attainment of a minimum soil temperature triggered gradual deacclimation that was unaffected by environment and immune to reacclimation. Loss of reacclimation ability could be explained by irreversible cellular and structural changes and/or a shortage of energy to reinitiate freezing tolerance (Pagter and Arora, 2013). For JG,
$\mathrm{LT}_{50}$ increased rapidly with rising soil temperatures; however, the cultivar appeared to partially reacclimate as soil temperatures cooled in 2012. GM showed no change in $\mathrm{LT}_{50}$ values during the sampling periods in both years. The irreversible increase in $\mathrm{LT}_{50}$ values for $\mathrm{UC}$ after soil temperatures began to increase would make it most susceptible to late spring freezethaw cycles and could explain its poor adaptation in Ontario. $\mathrm{LT}_{50}$ values for GM remained low and did not change during the sampling period suggesting the ability to withstand spring freezing events before emergence. JG may be susceptible to moderate freezing damage in some years, explaining, in part, its intermediate adaptation to southern Ontario and gradual decline.

Temporal levels of many metabolites associated with freezing tolerance followed the distinct soil temperature profiles of the 2 years: rapid increase followed by a decrease in 2012, and general linear increase over time in 2013. Traits included concentrations of rhizome and storage root LF, sucrose, proline, and glucose and water percentage, and rhizome raffinose and protein concentrations. The fluctuating levels of metabolites with temperature in 2012 for UC and GM are not congruent with the observed $\mathrm{LT}_{50}$ values, no change for GM and linear increase for $\mathrm{UC}$, and raises 


\section{Rhizome}
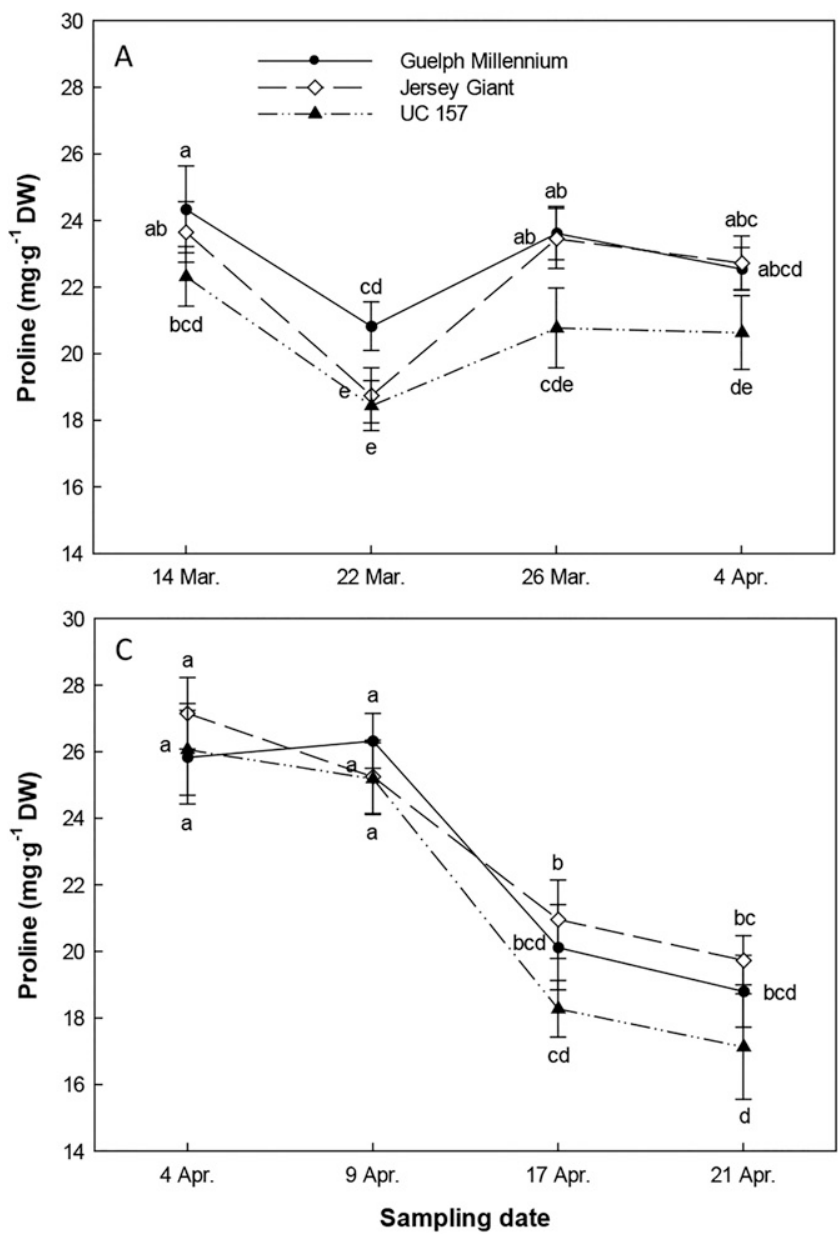

Storage root
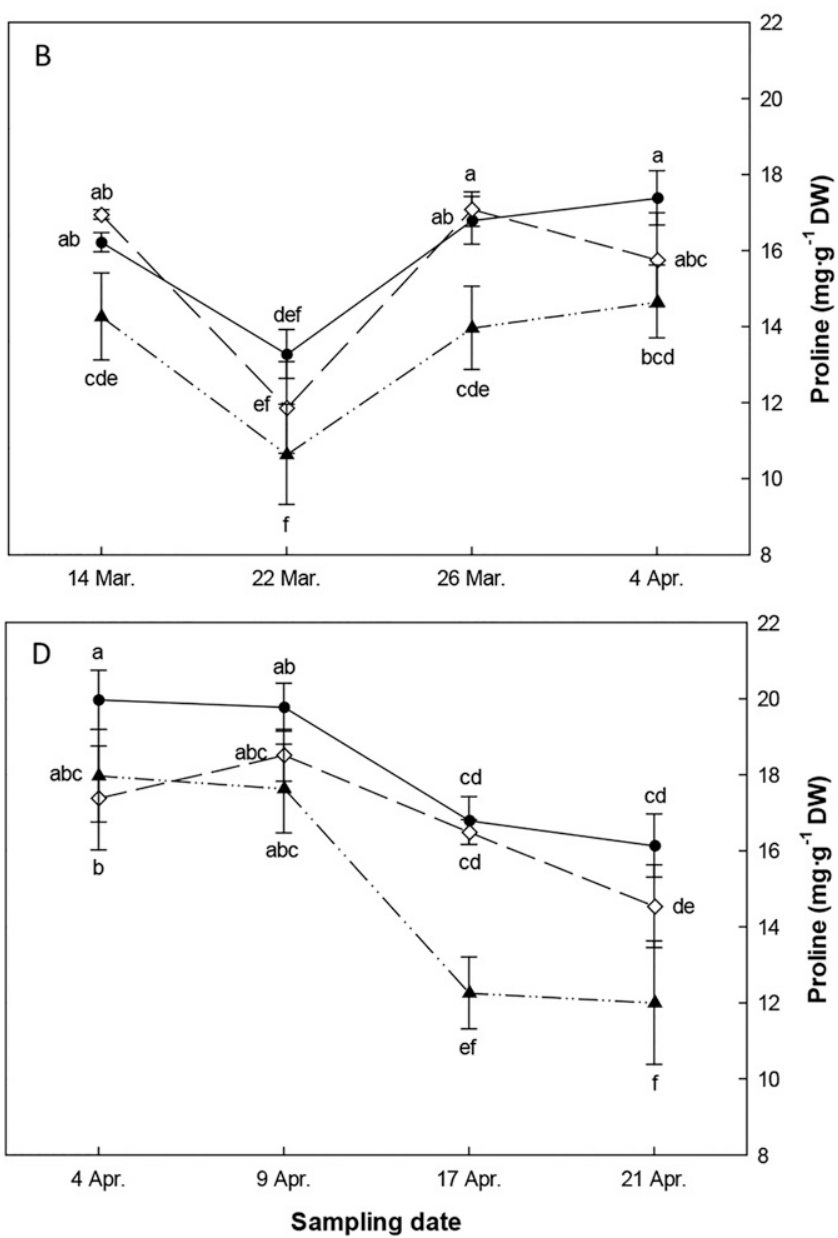

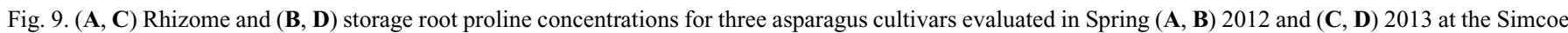
Research Station, Simcoe, ON, Canada. Vertical error bars represent the sE at each sampling date $(n=4)$. Letters indicate significant differences determined by Tukey's honestly significant difference $(P \leq 0.05)$.

questions as to the importance of physiological and biochemical parameters for predicting freezing tolerance when spring conditions fluctuate significantly or the occurrence of experimental error. The inconsistencies could be resulting from interactions of several compounds above or below threshold levels to provide freezing tolerance, or the contribution of other undetermined compounds. Alternatively, the chilling and freezing protocol for $\mathrm{LT}_{50}$ estimation could have resulted in reacclimation of plants and underestimates of true values, especially on the second sampling date in early Spring 2012, when soil temperatures were abnormally high.

Despite the discrepancy in patterns between $\mathrm{LT}_{50}$ and metabolites, UC and GM did differ for these parameters on specific dates in a manner consistent with increased freezing tolerance for GM, especially in the rhizome where high LF and raffinose and low sucrose concentrations in both years, and high glucose and proline concentrations and low water percentage in 2012 were observed. For comparisons across sampling dates when cultivars did not differ for $\mathrm{LT}_{50}$ values in both years, for example, UC and GM on the second and fourth sampling dates, respectively, many metabolites also did not differ, further supporting the value of the biochemical parameters for predicting freezing tolerance. The apparent deacclimation and reacclimation of JG in 2012 based on $\mathrm{LT}_{50}$ values was also supported by comparisons of metabolite data. Despite the different patterns of $\mathrm{LT}_{50}$ and metabolite levels in 2012, strong associations were observed overall such that levels of many metabolites can generally predict freezing tolerance both within and between sampling dates.

In summary, cultivars with varying levels of field adaptation to southern Ontario differed for freezing tolerance and associated metabolites during spring deacclimation, suggesting that a major component of winterhardiness may be the ability to tolerate spring freeze-thaw cycles. UC, the least-adapted cultivar that usually dies within 3 to 4 years of establishment, lost freezing tolerance linearly over time and was unaffected by fluctuating soil temperatures. GM, the most-adapted cultivar maintained low $\mathrm{LT}_{50}$ values, high freezing tolerance, during the spring sampling period. JG, the cultivar with intermediate adaptation, was susceptible to soil temperatures, decreasing freezing tolerance when soil temperatures rapidly increased but reacclimating moderately when soil temperatures decreased. The cultivars were most distinguished by differing concentrations of water or metabolites in the rhizome, suggesting the 

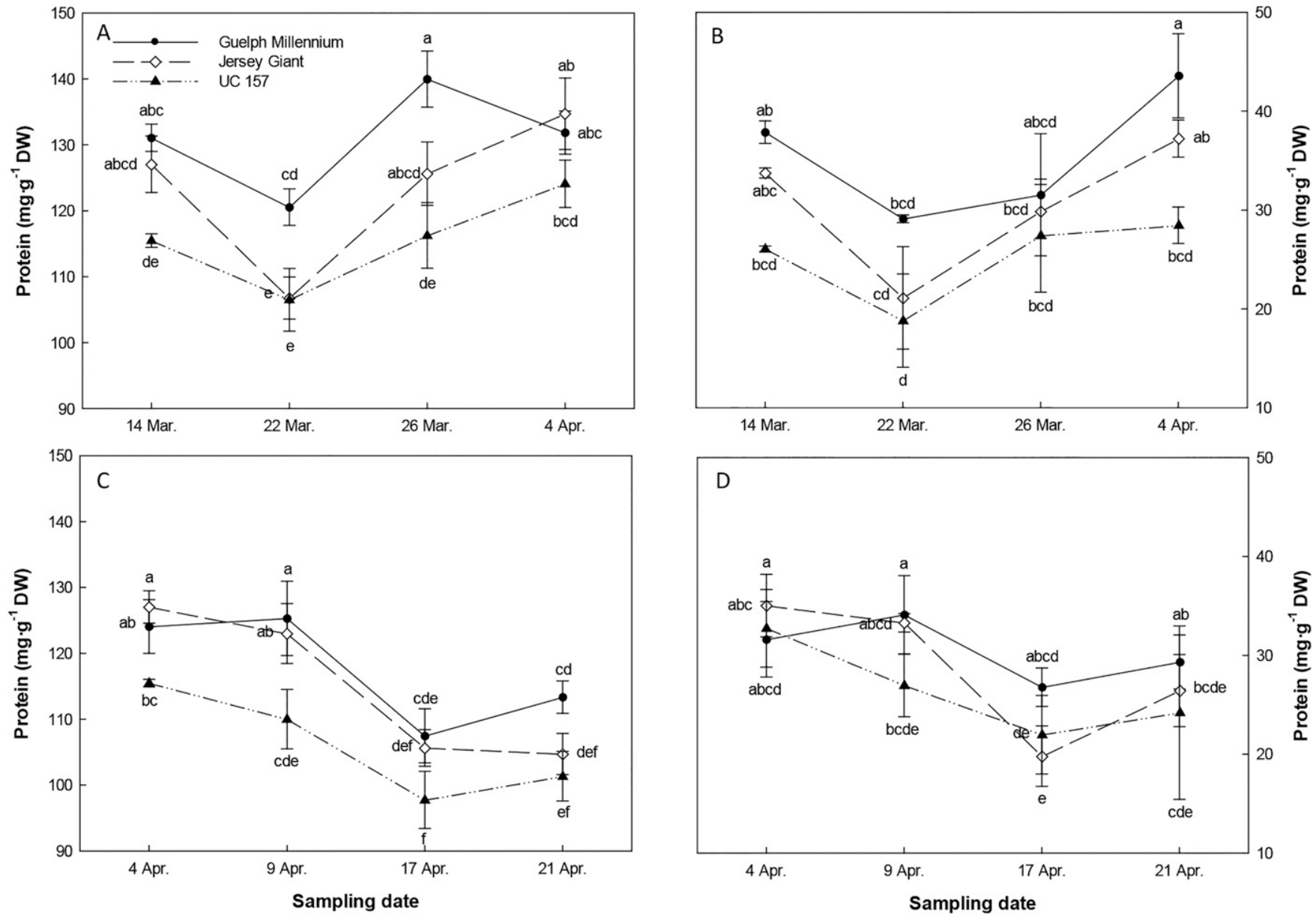

Fig. 10. (A, C) Rhizome and (B, D) storage root protein concentrations for three asparagus cultivars evaluated in Spring (A, B) 2012 and (C, D) 2013 at the Simcoe Research Station, Simcoe, ON, Canada. Vertical error bars represent the sE at each sampling date $(n=4)$. Letters indicate significant differences determined by Tukey's honestly significant difference $(P \leq 0.05)$.

Table 2. Pearson correlation coefficients between $\mathrm{LT}_{50}$, the temperature at which $50 \%$ of plants die, and biochemical and physiological parameters for three asparagus cultivars evaluated on four spring sampling dates in 2012 and 2013 at the Simcoe Research Station, Simcoe, ON, Canada.

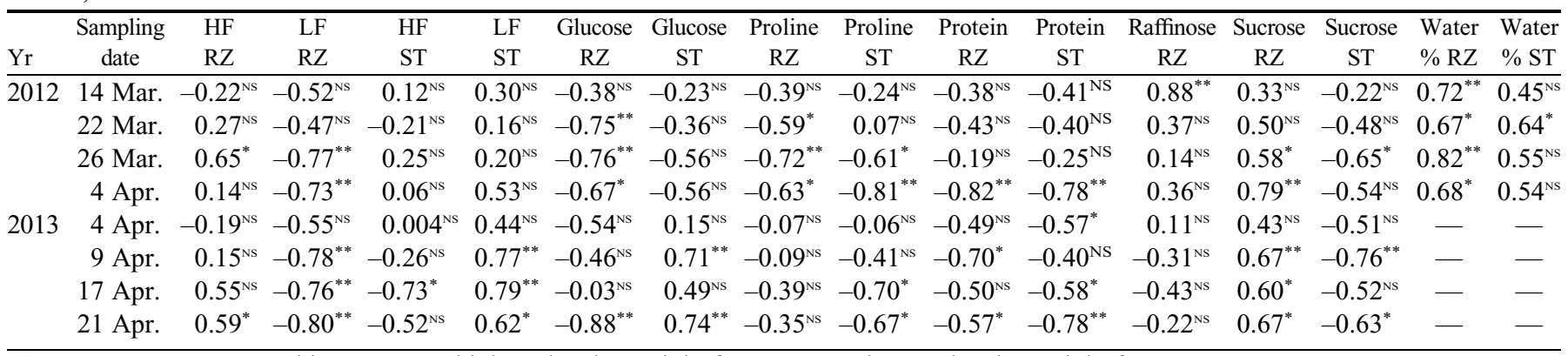

${ }^{\mathrm{z}} \mathrm{ST}=$ storage root, $\mathrm{RZ}=$ rhizome, $\mathrm{HF}=$ high-molecular-weight fructan, $\mathrm{LF}=$ low-molecular-weight fructan.

Ns,$*{ }^{*}$ Nonsignificant or significant at $P \leq 0.05$ or 0.01 , respectively.

freezing tolerance in this organ is most important for predicting adaptation.

\section{Literature Cited}

Arora, R., L.J. Rowland, and K. Tanino. 2003. Induction and release of bud dormancy in woody perennials: A science comes of age. HortScience 38:911-921.
Bradford, M.M. 1976. A rapid and sensitive method for the quantitation of microgram quantities of protein utilizing the principle of protein-dye binding. Anal. Biochem. 72:248-254.

Cairns, A. 1992. A reconsideration of fructan biosynthesis in storage roots of Asparagus officinalis L. New Phytol. 120:463473.

Fujikawa, S., Y. Jitsuyama, and K. Kuroda. 1999. Determination of the role of cold acclimation-induced diverse changes in plant cells 
from the viewpoint of avoidance of freezing injury. J. Plant Res. 112:237-244.

Guy, C. 2003. Freezing tolerance of plants: Current understanding and selected emerging concepts. Can. J. Bot. 81:1216-1223.

Herman, E., K. Rotter, R. Premakumar, G. Elwinger, R. Bae, L. EhlerKing, S. Chen, and D. Livingston, III. 2006. Additional freeze hardiness in wheat acquired by exposure to $-3{ }^{\circ} \mathrm{C}$ is associated with extensive physiological morphological, and molecular changes. J. Expt. Bot. 57:3601-3616.

Hoffman, L., M. DaCosta, and J.S. Ebdon. 2014. Examination of cold deacclimation sensitivity of annual bluegrass and creeping bentgrass. Crop Sci. 54:413-420.

Jørgensen, M., L. Østrem, and M. Höglind. 2010. De-hardening in contrasting cultivars of timothy and perennial ryegrass during winter and spring. Grass Forage Sci. 65:38-48.

Kishor, P.B.K., Z. Hong, G.H. Miao, C.A.A. Hu, and D.P.S. Verma. 1995. Overexpression of D1-pyrroline-5-carboxylate synthetase increases proline production and confers osmotolerance in transgenic plants. Plant Physiol. 108:1387-1394.

Kim, J. and D.J. Wolyn. 2015. Freezing tolerance assessment for seedlings of three asparagus cultivars grown under controlled conditions. Can. J. Plant Sci. 95:495-504.

Ku, Y.G., D.J. Woolley, A.R. Hughes, and M.A. Nichols. 2007. Temperature effects on dormancy, bud break and spear growth in asparagus (Asparagus officinalis L.). J. Hort. Sci. Biotechnol. 82:446-450.

Landry, E.J. and D.J. Wolyn. 2011. Cold acclimation attributes of two asparagus cultivars with varying patterns of fern senescence. J. Amer. Soc. Hort. Sci. 136:177-189.

Landry, E.J. and D.J. Wolyn. 2012. A method to assess cold acclimation and freezing tolerance in asparagus seedlings. Can. J. Plant Sci. 92:271-277.

Livingston, D., III. 1996. The second phase of cold hardening: Freezing tolerance and fructan isomer changes in winter cereal crowns. Crop Sci. 36:1568-1573.
Ontario Ministry of Agriculture and Food. 2004. Field crop protection guide. Ontario Ministry Agr. Food Publ. 812.

Pagter, M. and R. Arora. 2013. Winter survival and deacclimation of perennials under warming climate: Physiological perspectives. Physiol. Plant. 147:75-87.

Panjtandoust, M. and D.J. Wolyn. 2016. Asparagus cultivars with varying adaptation to southern Ontario differ for induction of freezing tolerance in the fall. Can. J. Plant Sci. (In press).

Patton, A., S. Cunningham, J. Volenec, and Z. Reicher. 2007. Differences in freeze tolerance of zoysiagrasses: I. Role of proteins. Crop Sci. 47:2162-2169.

Pressman, E., A. Schaffer, D. Compton, and E. Zamski. 1993. Seasonal changes in the carbohydrate content of two cultivars of asparagus. Sci. Hort. 53:149-155.

Tanino, K., C. Weiser, L. Fuchigami, and T. Chen. 1990. Water content during abscisic acid induced freezing tolerance in bromegrass cells. Plant Physiol. 93:460-464.

Sãulescu, N.N. and H.J. Braun. 2001. Cold tolerance, p. 111-123. In M.P. Reynolds, J.I. Ortiz-Monasterio, and A. McNab (eds.). Application of physiology in wheat breeding. CIMMYT, Texcoco, Mexico.

Suzuki, M. 1981Responses of alfalfa to a simulated midwinter thaw, p. 390-393J.A. Smith and V.W. Hays (eds.). Proc. 14th Intl. Grasslands Congr., Westview Press, Boulder, CO.

Vagujfalvi, A., I. Kerepesi, G. Galiba, T. Tischner, and J. Sutka. 1999. Frost hardiness depending on carbohydrate changes during cold acclimation in wheat. Plant Sci. 144:85-92.

Valluru, R. and W. Van den Ende. 2008. Plant fructans in stress environments: Emerging concepts and future prospects. J. Expt. Bot. 59:2905-2916.

Verbruggen, N. and C. Hermans. 2008. Proline accumulation in plants: A review. Amino Acids 35:753-759.

Zhang, X. and E.H. Ervin. 2008. Metabolic defense responses of bermudagrass during acclimation to freezing stress: A review. Acta Hort. 783:181-194. 